\title{
Judith Urbano
}

\section{NOVES APORTACIONS SOBRE LA FAÇANA I EL PATI DE LA CASA GRALLA}

La Casa Gralla, al carrer de la Portaferrissa de Barcelona, era de la família Desplà. Un dels personatges més rellevants de la família fou I'ardiaca Lluís Desplà i Oms (1444-1524); la seva neboda, Anna Desplà i de Corbera, es casà I'any 1506 amb el noble Miquel-Joan Gralla. Sabem que I'edifici ja existia I'any 1306, però el 1518 Miquel-Joan Gralla el va reformar, especialment la façana, d'estil renaixentista, admiració de la Barcelona del moment. El 1856 es va obrir el carrer del Duc de la Victòria i es va tirar a terra el palau. Les pedres van anar a parar al baluard de Tallers; algunes van ser adquirides per particulars, com es veurà, i la resta, malauradament, van acabar com a runa abocades al mar, a l'escullera del port. ${ }^{1}$

Abordem els tres aspectes d'aquesta història menys coneguts i tractats per la historiografia: les pedres originals, mai abans fotografiades, que encara existeixen a la Torre Pallaresa de Santa Coloma de Gramenet; els dibuixos originals de Francesc Soler i Rovirosa, recentment descoberts i que es consideraven perduts, i el projecte d'August Font i Carreras, de 1907, per adaptar la nova casa de la marquesa de Brusi al pati de la Casa Gralla a Sant Gervasi.

Pel que fa al primer aspecte, Duran i Sanpere és qui aporta més dades, perquè dedica diverses pàgines a la Casa Gralla i també a la Torre Pallaresa. ${ }^{2}$ El fabricant Albert Coll i Vallès, en comprar la residència de Santa Coloma I'any 1867, la va arranjar al seu gust. Podria ser llavors quan va trobar les pedres abandonades al baluard de Tallers de la muralla de Barcelona. Aquesta és una hipòtesi perfectament viable perquè, en aquell moment, no existia una preocupació sobre temes patrimonials. A la Torre Pallaresa, com es veurà, hi ha llindes renaixentistes usades com a llars de foc i moltes portes estan emmarcades amb aquests elements, amb decoració a la part superior i mènsules als costats. En la majoria, a la part de baix dels brancals hi ha decoració geomètrica molt característica. Es fa
${ }^{1}$ Quant a la bibliografia sobre el tema, s'ha de fer referència a alguns estudis. La casa apareix mencionada en el llibre de Pau Piferrer, Recuerdos y bellezas de España, vol. 2, Barcelona, Impremta de Joaquín Verdaguer, 1839, on hi ha una litografia de Xavier Parcerisa que mostra la porta renaixentista, des d'on es veu l'entrada de la casa amb un sostre enteixinat de fusta i, al fons, una part del pati. El clàssic Catálogo Monumental de España. La ciudad de Barcelona, Madrid, Consejo Superior de Investigaciones Científicas, 1947, de Joan Ainaud, Josep Gudiol i Frederic Pau VerRIÉ, explicava l'itinerari de les pedres del pati fins aleshores i citava explícitament la pèrdua dels dibuixos de Soler i Rovirosa. Criticava I'escampament de les pedres $i$ on havien acabat. En aquell moment, el pati es trobava a Can Brusi i no es podia pensar que encara li faltaven més viatges i canvis d'emplaçament. Agustí DuRAN I SANPERE a Barcelona i la seva 
història, vol. 1, Barcelona, Curial, 1972, aportava una dada significativa: el fet que la Casa Gralla gairebé es va salvar de la piqueta per la iniciativa de I'arquitecte Miquel Garriga de convertir la façana renaixentista en I'entrada magnificent d'un basar que arribaria fins al carrer de la Canuda; fins i tot va ser publicat en premsa, però dies després es van haver de desdir en el mateix diari, ja que malauradament no va ser possible. Malgrat les veus que van sorgir a favor de salvar la casa, res no es va aturar. També cal citar un llibre de 1997, de diferents autors, publicat amb motiu de la reconstrucció del pati dins la seu central de l'empresa Prosegur: Pedro NAvAscuÉs, El patio de la Casa Gralla. Una reconstrucción, Madrid, Prosegur, 1997. Hi destaquen els articles de Josep Maria AinAUd DE LASARTE amb la història dels Desplà i de la casa, i el de José Miguel Merino de CÁceres sobre els diferents trasllats del pati. EI Dr. Joaquim GARRIGA protagonitza la darrera aportació en aquest respecte: un extens i exhaustiu article amb motiu de la troballa d'un quadern d'Elies Rogent que contenia dibuixos de la casa just abans del seu enderrocament: «La peripècia de la Casa Gralla i un quadern d'Elies Rogent de 1856», Butlletí de la Reial Acadèmia Catalana de Belles Arts de Sant Jordi, n. 18, Barcelona, 2004.

2 Agustí Duran i SAnPere, op. cit. (sobre la Casa Gralla, p. 535-541; sobre la Torre Pallaresa, p. 741-744). difícil establir quines d'aquestes Ilindes provenen de la Casa Gralla, a excepció de les que tenen l'escut familiar que ara analitzarem, però podria ser que les que no podem identificar per cap element distintiu també provinguessin de la casa. El que és segur és que cap pertanyia al treball de la façana, com demostren els dibuixos de Soler i Rovirosa; per tant, serien elements arquitectònics de l'interior, del qual, malauradament, no tenim cap descripció.

I és que algunes d'aquestes Ilindes tenen un element que indiscutiblement reforça la teoria de Cèsar August Torras i Agustí Duran i Sanpere, i que, per tant, ens permet afirmar que procedeixen de la casa de Portaferrissa: I'heràldica que hi tenen representada és la de la família Gralla. ${ }^{3}$ El seu escut és quarterejat, amb una gralla al primer i al quart quarters, i als altres dos, camper de losanges amb bordura de vuit roses, que seria la part dels Desplà, i, a sobre, una àguila. És I'escut resultant del matrimoni entre Anna Desplà i Miquel-Joan Gralla I'any 1506 (fig. 1). L'any 1527, el seu fill, Francesc Gralla i Desplà, es casà amb Guiomar o Violant d'Hostalric-Sabastida. Així, l'escut es va dividir en dos de manera vertical: una part seria igual que I'esmentada, la dels Gralla-Desplà, i I'altra, dues franges verticals en zigazaga (fig. 2). Per tant, serien Ilindes de moments cronològicament diferents, anterior i posterior, respectivament, a aquest darrer matrimoni.

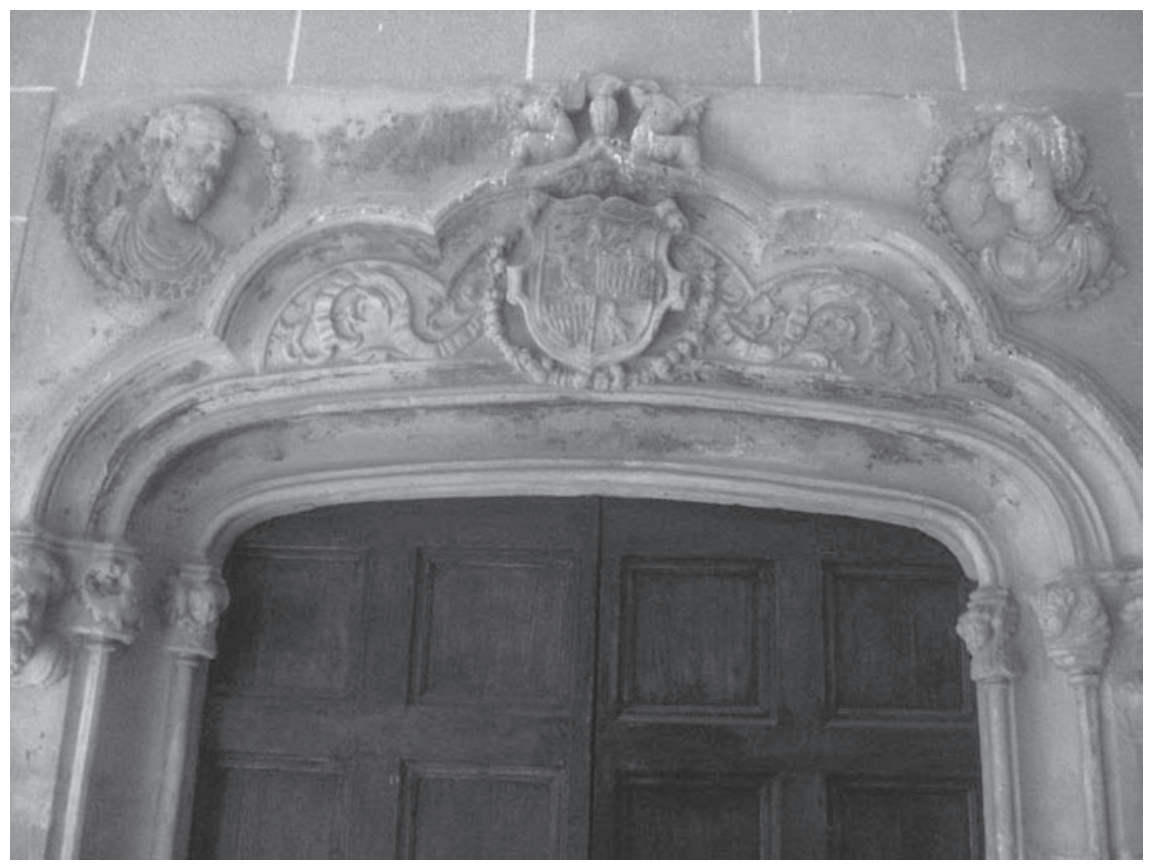

1. Escut de la família Gralla-Desplà. Fotografia: Judith Urbano. 
En total, hi ha cinc d'aquestes Ilindes a la Torre Pallaresa, en les 3 Ibídem, p. 742. quals podem reconèixer I'heràldica familiar de la casa de Portaferrissa: una amb I'escut Gralla-Desplà, ara amb la mateixa funció (fig. 3), i quatre amb escuts Gralla-Desplà/Hostalric-Sabastida. D'aquestes quatre, dues encara fan la funció de llinda (fig. 4 i 5) i les altres dues han estat convertides en el marc de dues llars de foc (fig. 6 i 7 ). Els busts de personatges dins de medallons i la vegetació ornamental exuberant, amb animals fantàstics (com ara grius) i criatures amb caps humans que trobem sobre algunes de les portes, són molt propers estilísticament a les decoracions de les finestres de la façana principal de la Casa Gralla, com analitzarem seguidament. Podrien ser, per tant, Ilindes corresponents a l'interior de la casa, espais de pas entre estances rellevants.

El segon punt que es volia destacar en aquest estudi és la troballa dels dibuixos originals de Francesc Soler i Rovirosa. Es conserven entre els documents de I'arxiu familiar de I'arquitecte August Font i Carreras, a qui estan dedicats per l'artista. Soler i Rovirosa va fer, a la primera pàgina, un esquema de la façana en què va numerar totes les finestres que hi havia, de la 1 a la 15, i en tres registres de dalt a baix, si bé cal dir que les del registre central no estan ben alineades amb les de sota, quan, com es pot veure en les fotografies antigues, la correspondència era total.

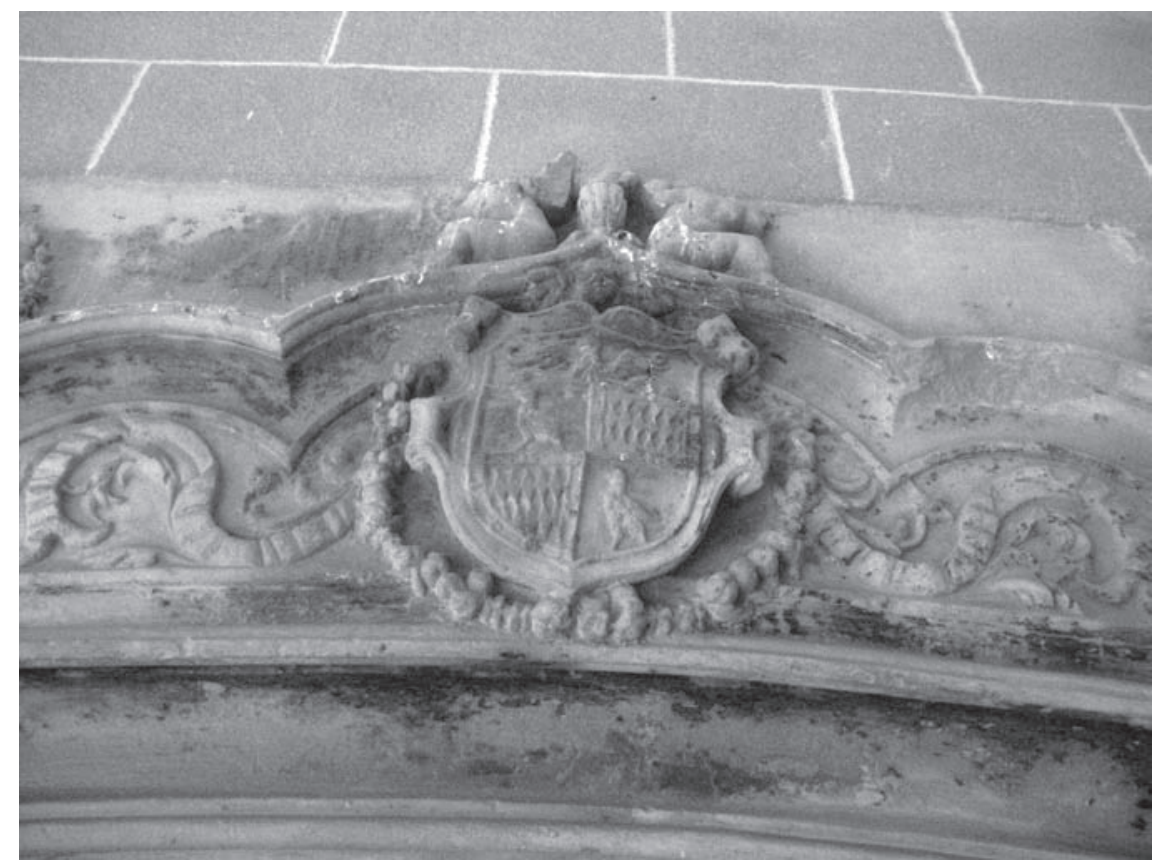

2. Escut de la família Gralla-Desplà/Hostalric-Sabastida. Fotografia: Judith Urbano. 


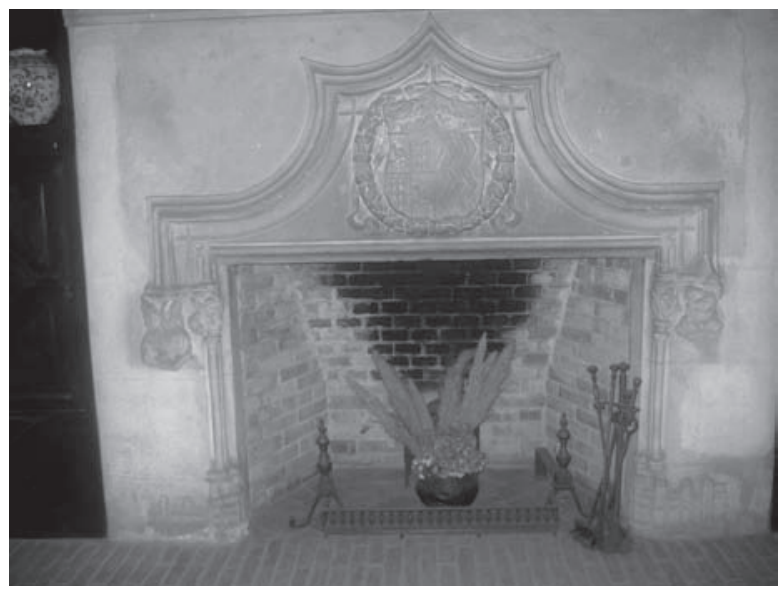

3. Llinda de la Casa Gralla a la Torre Pallaresa amb l'escut dels Gralla-Desplà. Fotografia: Judith Urbano.

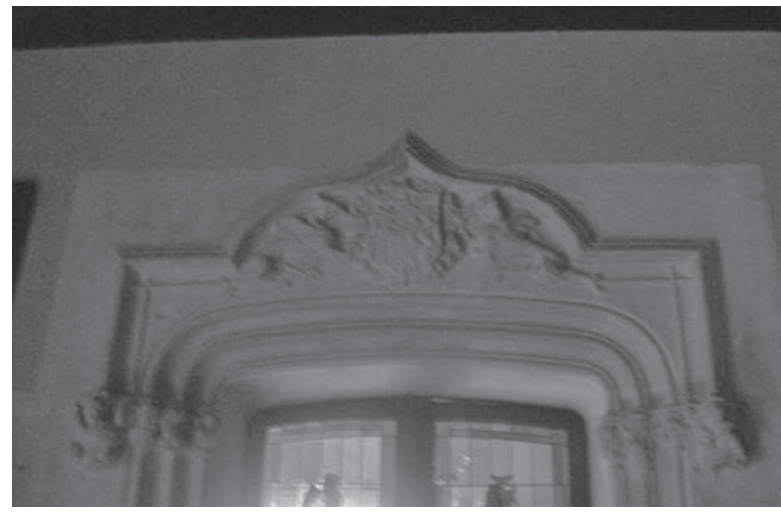

5. Llinda a la Torre Pallaresa amb l'escut Gralla-Desplà/ Hostalric-Sabastida. Fotografia: Judith Urbano.

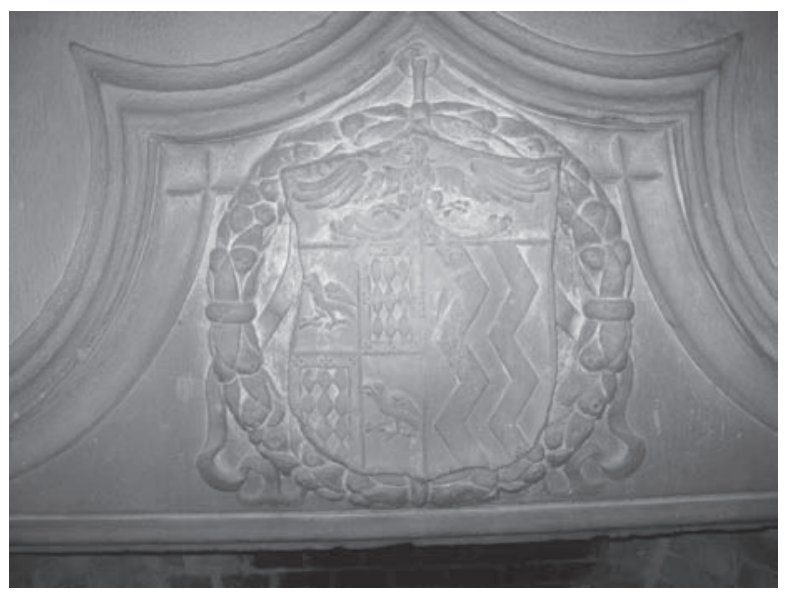

4. Llinda a la Torre Pallaresa amb l'escut Gralla-Desplà/ Hostalric-Sabastida. Fotografia: Judith Urbano.

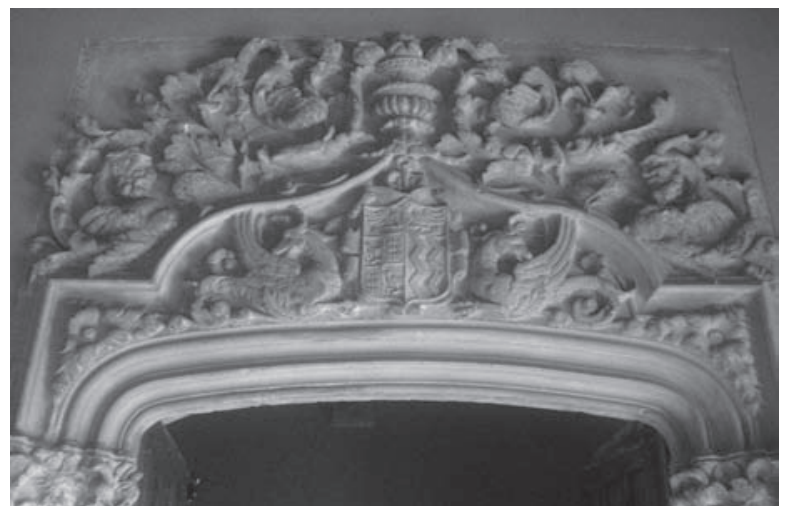

6. Llinda de la Casa Gralla convertida en marc per a llar de foc a la Torre Pallaresa amb l'escut dels Gralla-Desplà/HostalricSabastida. Fotografia: Judith Urbano. 


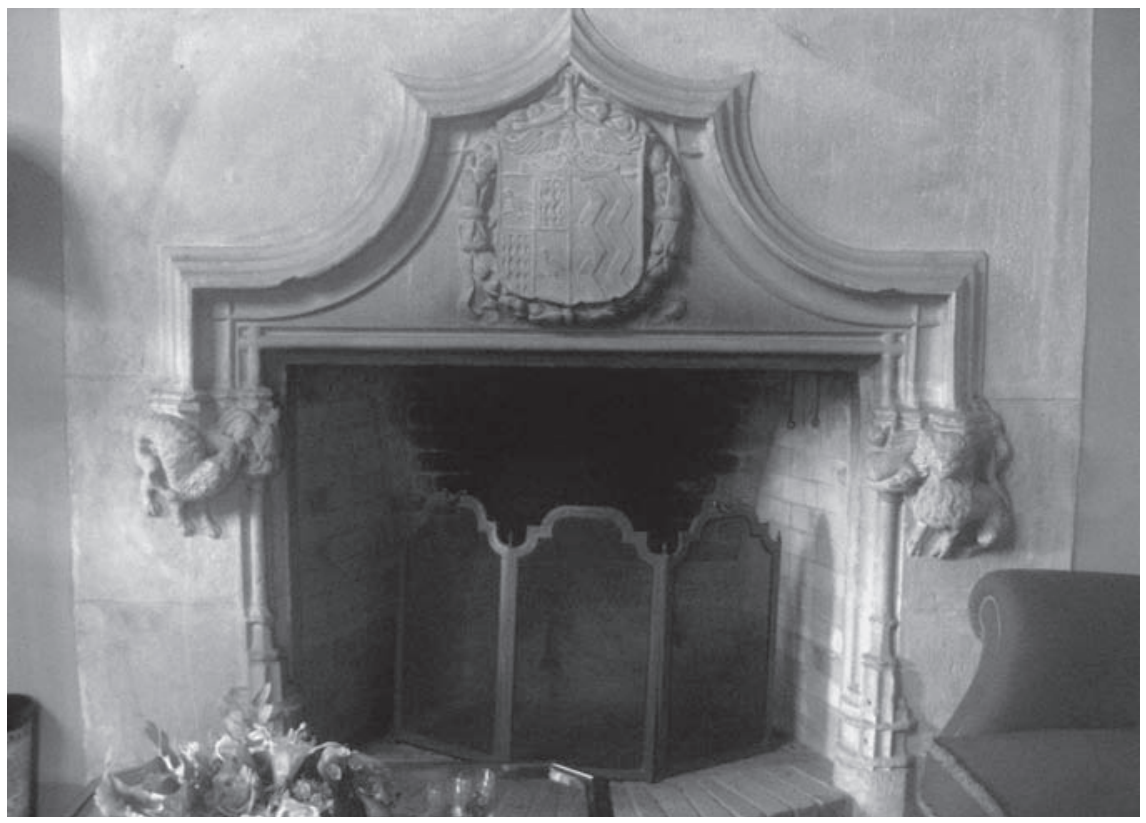

7. Llinda de la Casa Gralla convertida en marc per a llar de foc a la Torre Pallaresa amb l'escut dels Gralla-Desplà/Hostalric-Sabastida. Fotografia: Judith Urbano.

L'única finestra que quedava desaparellada era la número 14, just al costat esquerre de la porta d'entrada, que no tenia cap altra obertura a sobre. En totes les il-lustracions, les finestres estan representades tan sols en una meitat, per la qual cosa entenem que la seva ornamentació era simètrica. A la primera pàgina hi ha l'esmentat esquema de la façana i un sol dibuix que correspon a les finestres 1 i 2, situades a la part alta de la casa, a les torres, simètricament disposades. Estarien emmarcades per dues pilastres planes corínties, amb estries tan sols a la part superior (element que ja veurem que és recurrent i que també apareix en les columnes del pati), i coronades per un fris amb tríglifs i mètopes sense decorar. Com ja es veurà, són les úniques finestres de la façana que no tenen pedestal, potser perquè són les que es troben a més alçada, i tenen pilastres en lloc de columnes (com també passa a les finestres número 12 i 13). A sobre, una filera de denticles deixa pas al timpà arrodonit amb un relleu que als extrems té una copa amb foc. $A$ aquest dibuix, s'hi afegeix el d'una mènsula, que correspon a l'acabament de la cornisa de la casa a la cantonada. La mènsula té forma d'escut (no s'hi veu I'heràldica dibuixada, tot i que és de suposar que seria la de la família Gralla) amb el cap d'un animal al darrere.

El dibuix següent és únicament la finestra 4 (fig. 8), emmarcada per columnes corínties estriades en la part superior que descansen sobre un 
${ }^{4}$ Com s'ha dit, I'alineació de les finestres en I'esquema de Soler i Rovirosa no és ajustada a la realitat. En les litografies de Parcerisa, una aquarel-la de Joan Fatjó existent al Museu $d^{\prime}$ Història de la Ciutat o el dibuix d'Elies Rogent al seu quadern de notes, es pot veure la disposició correcta de les finestres. pedestal decorat amb un gerro amb flors. El fris superior és continu, amb elements vegetals sinuosos. L'ornamentació més sumptuosa és a la part superior de la finestra, on es barregen elements naturals i animals amb putti que sostenen un medalló amb un retrat d'home de perfil, barbat i amb corona de llorer. A sobre, hi ha un gerro amb fruits i raïm que sobresurt pels costats. Aquesta decoració no acaba sobre la finestra, sinó que cau a cada banda en forma de garlanda de flors i llaços. La part inferior també està molt decorada, i el seu dibuix enllaça amb la part superior de la finestra que hi està alineada (correspondria a la número 11). És I'única vegada que ho fa així, de manera que al dibuix de la finestra 11 no hi afegirà aquesta part. Entenem que ho fa perquè es pugui apreciar aquesta alineació entre finestres i, a la vegada, aquesta adequació de l'escultura a ambdós elements arquitectònics. D’aquí que sigui també l'únic dibuix amb disposició vertical. S'hi aprecien caps barbats, putti amb cornucòpies plenes a vessar, un pegàs dirigit per un nen amb una vara i un element central en forma de cartel.la que ocuparia l'espai entre les dues finestres, la superior i la inferior.

Seguidament estan dibuixades les finestres 3 i 5, és a dir, les que quedaven a cada banda de l'anterior. Els marcs d'ambdues finestres contenen, de fet, els mateixos elements explicats, amb lleugeres diferències. També enllaçarien amb les finestres de la part inferior, amb les números 10 i 12 respectivament. La número 3 està emmarcada per columnes corínties estriades amb un pedestal decorat amb una màscara; per sota de I'ampit hi ha una mènsula que recull una garlanda provinent de l'ornamentació de la finestra 10 i que, a l'altra banda, continua en forma de filacteri. La Ilinda de la finestra és un fris decoratiu continu amb elements vegetals. La part de sobre conté el bust d'un home envoltat de fulles i de dos animals fantàstics. Tot això, coronat per la figura d'un àngel. També, a cada banda de la finestra, cauen garlandes amb poms de fulles.

La número 5 té el mateix emmarcament que l'anterior, amb pedestal ornamentat amb un gerro de flors. Sota la finestra, la mènsula s'ha convertit en una màscara que s'entrellaça amb una tija. També hi ha un ocell i un putto. La part superior porta un medalló central emmarcat per garlandes florals on hi ha el bust d'una dona amb diadema i el cabell recollit. L'acompanya una tija que acaba en un cap d'animal, sostinguda per un putto sobre una cornucòpia. Tot el conjunt està coronat per un gerro amb flors suportat per un animal semblant a un griu.

Segueixen els dibuixos de les finestres 6 i 7. A sota, la 6 es correspon amb la 13, però la número 7 quedaria just sobre la porta principal de la casa, enllaçant amb la rica ornamentació d'aquesta porta. ${ }^{4}$ Tant a la finestra 6 com a la 7, els emmarcaments són iguals que en les anteriors, a excepció del fris de la número 6, que té una tija vegetal que surt del cap 


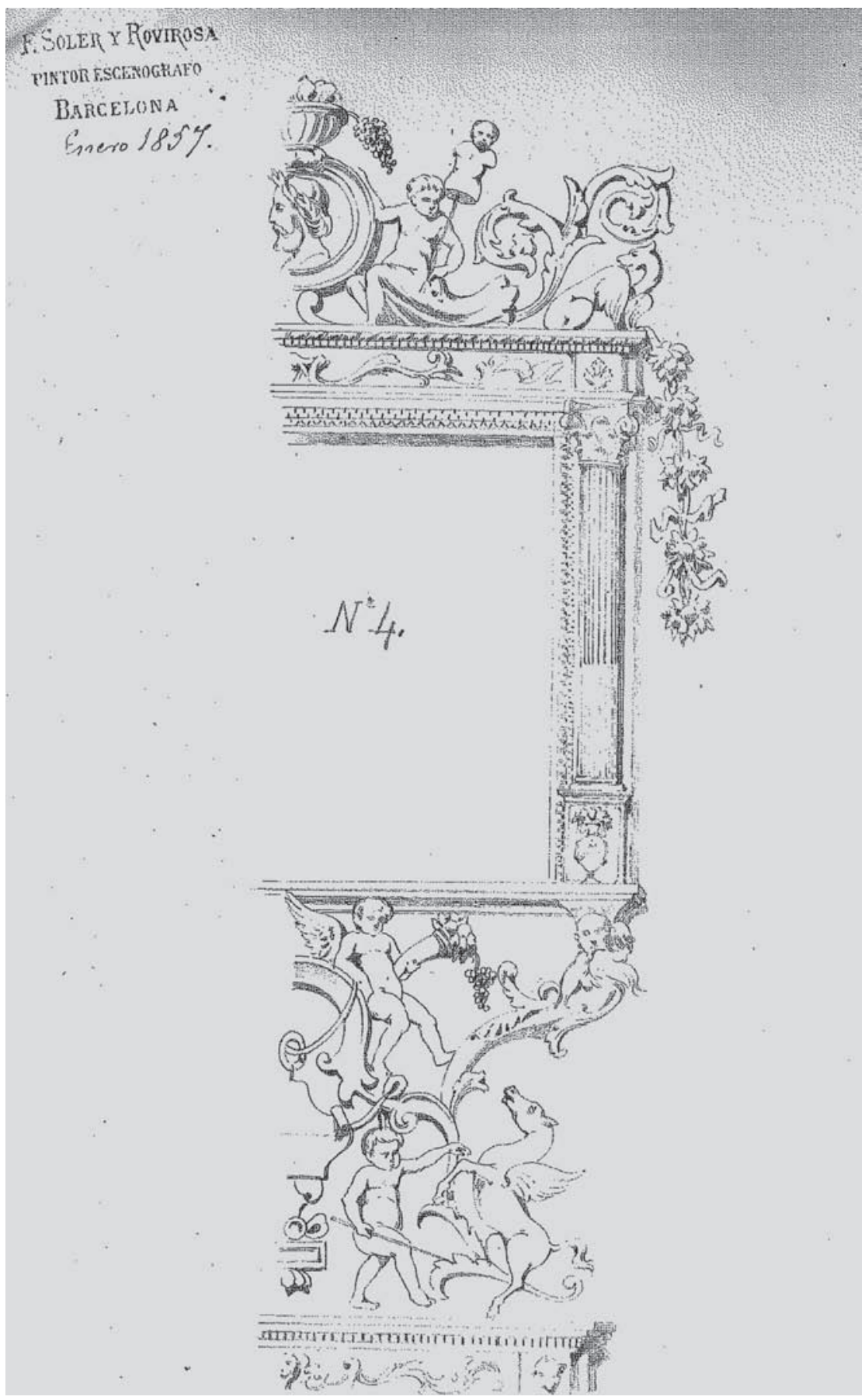

8. Dibuix de Francesc Soler i Rovirosa de la finestra número 4 amb el seu segell i, escrita a mà, la data «Enero 1857». Arxiu Maria Font. 
d'un querubí. El pedestal té una font representada i la part baixa de la columna, unes estries helicoïdals. Sota la finestra, hi ha una màscara central, una garlanda amb dues campanetes als extrems i mènsula i filacteri com a la número 3. Sobre la finestra, un bust d'home barbat dins d'un medalló vegetal, envoltat de tiges i animals fantàstics (el de l'extrem, amb cara d'home amb barba i ales).

La número 7 ornamenta el pedestal amb una planta que surt d'un test. La part baixa, l'ocupen una garlanda vegetal que surt d'una petxina central i un Ilaç. Hi ha també una figura humana, que és la que quedaria sobre la porta principal. Sobre la finestra, hi ha un medalló amb un bust de dona de perfil envoltat de fulles i un nen tocant un corn. A sobre, s'hi observa la representació d'un gerro del qual surt un cap masculí amb grans fulles.

Seguidament, ens fixem en les finestres 8 i 9. La 8 queda a la part superior dreta de la porta i la 9 té a sota la número 15. La 8, com la 7, que li fa de parella sobre l'entrada, també té a la part baixa una petxina i una garlanda vegetal. La part superior és ocupada per un altre medalló, amb un personatge masculí de perfil i amb corona, mirant cap a la dona de la finestra 7. Sobre el medalló també hi ha un gerro amb grans fulles, acompanyat d'un putto que sosté una màscara d'un home barbat.

La número 9 té, a la part baixa, un bucrani amb una garlanda que va a parar a una màscara central. La decoració de sobre la finestra inclou figures humanes, garlandes i una mena de griu, tot coronat per un putto.

Les finestres 10 i 11 són les primeres del registre inferior de la façana. La decoració de sobre la primera consisteix en un gerro aguantat per un putto amb garlandes de fulles i una au a l'extrem. A sota de la finestra, hi ha un medalló central d'elements florals amb un bust femení de perfil i dues figures a l'extrem.

La finestra 11 no té dibuixada la decoració de la part superior, perquè ja consta en el dibuix de la finestra 4, que, com s'ha explicat, ocupava tota una pàgina. Tan sols hi ha la part de sota, molt semblant a la número 10, ja que hi apareix un medalló amb un bust masculí de perfil, mirant cap a la dona de la finestra anterior. Va acompanyat d'un griu i una figura barbada.

La pàgina següent és I'única amb tres finestres dibuixades: la 12, la 13 i la 14, que queden al costat esquerre de la porta d'entrada (fig. 9). La primera té una pilastra emmarcant la finestra, amb el pedestal ornamentat amb una màscara. El fris està decorat amb una sanefa que alterna àngels i aus de dos caps. La part inferior inclou un bust d'home de perfil, acompanyat de grans fulles i d'una figura masculina barbada. La part de dalt inclou I'escut dels Desplà-Gralla, del qual es poden albirar les gralles i els losanges. Està aguantat per un putto que mira una figura femenina i un cap d'animal. 


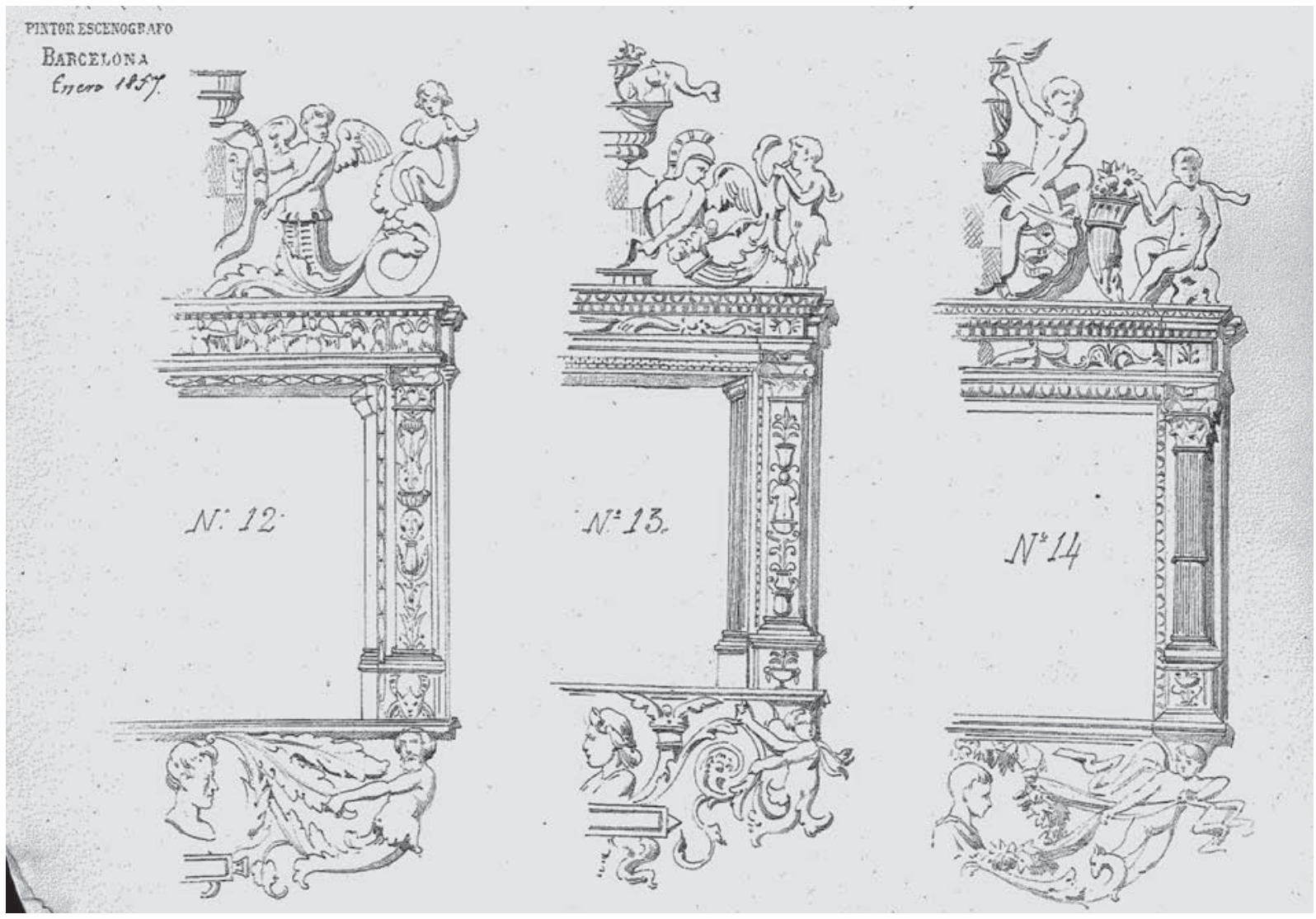

9. Dibuix de Francesc Soler i Rovirosa de les finestres número 12, 13 i 14, amb el seu segell i, escrita a mà, la data «Enero 1857». Arxiu Maria Font.

La finestra número 13 també té pilastra i pedestal al marc, amb decoració de gerros. A sota, hi ha un bust de dona amb diadema, mirant cap a I'home de la finestra anterior, rodejat de garlandes agafades per una figura. La part de sobre consta d'un gerro amb un animal que mira les imatges inferiors, que són un personatge amb un casc romà al cap i un sàtir.

La finestra 14 torna a tenir una columna emmarcant-la. La decoració de sota és un bust d'home dins d'un medalló vegetal i un putto que agafa unes bandes de roba que hi són enllaçades. A la part superior, s'hi observa un escut del qual només es veuen dos quarters amb losanges, coronat amb un gerro i amb dues figures masculines amb cornucòpia. Aquesta és la finestra que queda just al costat de la porta de la Casa Gralla i que no té correspondència amb cap finestra al pis superior. 
5 Si bé tradicionalment s'ha atribuït la façana a Damià Forment, no hi ha documentació que ho pugui confirmar. Xavier de Salas va comparar l'obra de Poblet amb la de la Casa Gralla i va arribar a la conclusió que són de la mateixa mà, basant-se en la decoració de la porta i I'estil dels putti i les garlandes. Xavier de SALAS: "Escultores renacientes en el Levante español», a Anales y Boletín de los Museos de Arte de Barcelona, vol. 1, Arte Antiguo, Barcelona, 1941, p. 79-92.

6 Vegeu La I/·lustració Catalana, Barcelona, 15 de març de 1882, p. 83: «el pati ha estat reconstruït pel Marquès de la Casa Brusi a la magnífica hisenda de sa propietat a Sant Gervasi de Cassoles i per tant laudable medi pot encara apreciar-se [... ] els restos de la casa encara corren avui per Martorell en Casa Santacana i per los entorns de la Torre Pallaresa, prop de Badalona». En I'article es refereixen a la Casa-Museu "L'Enrajolada», del col·leccionista Francesc Santacana, i a la Torre Pallaresa de Santa Coloma de Gramenet, ja comentada.
L'última pàgina es dedica a la finestra 15, que queda al costat dret de la porta d'entrada, just a sota de la número 9. A la part inferior hi ha un bust central, de perfil, amb casc, emmarcat per un arc que és tensat per un putto. A dalt, hi ha un escut quarterat l'interior del qual no està dibuixat, aguantat per un putto i coronat per un gerro amb flors. A I'extrem, s'hi veu un altre putto sortint d'un gerro.

Amb aquesta revisió dels dibuixos de Soler i Rovirosa, se'ns mostra la riquesa ornamental d'aquest conjunt. L'escultura «a la romana», la filigrana del relleu i el gran ventall d'elements diferents que hi trobem (putti, garlandes, bucranis, medallons, busts, animals fantàstics, Ilaços...) demostren que ens trobem davant d'un artista amb bons models iconogràfics. Quant a la identitat d'aquest artista, de tots és sabut que el nom de Damià Forment ha estat considerat com una possibilitat i, potser, els dibuixos dedicats a August Font podran aportar més informació en aquest respecte. ${ }^{5}$ Alhora, es pot apreciar la gran pèrdua que va significar per a la ciutat I'enderroc de la Casa Gralla, que devia ser el millor exemple de palau renaixentista a Barcelona en aquell moment, i que ho seria ara si hagués perdurat, no només per la decoració exterior, sinó també per la interior, tal com es pot comprovar per les Ilindes de la Torre Pallaresa mostrades en aquest article.

Per finalitzar, el tercer aspecte és la tasca de I'arquitecte August Font i Carreras (1845-1924) en el trasllat del pati de la Casa Gralla a la finca del marquès de Brusi a Sant Gervasi.

Com ja s'ha comentat, I'any 1856 s'enderrocà la Casa Gralla per obrir el carrer del Duc de la Victòria, i les pedres renaixentistes acabaren a la muralla del baluard de Tallers. Antoni Maria Brusi i Ferrer (1815-1878), marquès de Brusi i director del Diario de Barcelona, va comprar-ne unes restes I'any 1881, pensant que eren les de la façana. Però descobrí que eren les pedres del pati, així que va encarregar a August Font que el muntés i I'acoblés a la torre que tenia al carrer d'Alfons XII, però això aviat es va veure inviable, perquè les mides no coincidien amb les de la casa, així que es decidí reconstruir-lo enmig del jardí com a edifici independent. Antoni Maria Brusi va decorar aquest pavelló amb els mobles, tapissos, armes, ceràmica i altres objectes de la seva col-lecció d'antiguitats i la premsa de l'època se'n va fer ressò. ${ }^{6}$

El pati era de planta gairebé quadrada, amb alçat a tres nivells segons la tipologia gòtica. El nivell inferior presentava un gran arc carpanell per costat, sobre quatre columnes angulars de fust Ilis i capitell corinti amb volutes invertides, amb una aparença molt lleugera. Al segon nivell, una galeria d'arcs ogivals, tres a cada costat, separats per columnes estretes amb capitell corinti. El fust d'aquestes columnes és estriat i està dividit en 
dos, com era el cas de les columnes i pilastres que emmarcaven les diferents finestres de la façana de la Casa Gralla, com s'ha vist en les illustracions de Soler i Rovirosa. L'ampit era força alt i estava decorat amb traceria calada. El tercer nivell tenia cinc finestres per costat, formant una galeria. Hauria estat, originàriament, un dels exemples més reeixits de combinació d'elements gòtics i renaixentistes en un mateix edifici.

El 1907, Maria Josefa Brusi, filla del marquès, que ja havia mort, decideix enderrocar la casa familiar i encarregar a August Font i Carreras la construcció d'una casa nova al voltant del pavelló del pati de la Casa Gralla. ${ }^{7}$ En els plànols existents a l'Arxiu Administratiu Municipal de Barcelona i en els del Col-legi Oficial d'Arquitectes de Catalunya es veu perfectament l'adaptació del pati a la nova casa, tot i que són insuficients per determinar la distribució de les habitacions.

Seguint els plànols, la casa tenia planta baixa amb canvi de cota, principal i primer. La seva coberta era a doble vessant. Al costat sud-oest $\mathrm{s}^{\prime}$ alçava una torre amb galeria de finestres superior i tribuna al principal. L'entrada de la casa era per la façana sud, sota un arc de mig punt, i, a sobre, al principal, hi havia un balcó amb tres arcs conopials suportats per quatre columnes. A la dreta, Font hi dissenyà una torre estreta. Però ni els arcs ni aquesta torre van ser construïts finalment, a jutjar per I'única fotografia existent que $\mathrm{s}^{\prime}$ ha pogut trobar. ${ }^{8}$

Malauradament, I'any 1964, quan es va reordenar la plaça Molina, I'edifici Brusi resultà afectat. El pati es va desmuntar i les més de 600 pedres van arribar a un dipòsit a Cornellà. D'allà viatjaren a Mijas, Màlaga, ja que les va comprar un antiquari. Finalment, foren adquirides per Herbert Gut, president de I'empresa Prosegur, que va encarregar a I'arquitecte Octavio Mestre que bastís de nou el pati a la seu central de l'empresa, a I'Hospitalet de Llobregat, I'any 1995, on es troba en I'actualitat. ${ }^{9}$

Els anys, els viatges i la falta de polítiques sobre patrimoni han fet que la malaguanyada Casa Gralla hagi quedat esquarterada, i les seves pedres escampades per diferents llocs. Tot i això, encara hi ha suficient informació per localitzar-ne algunes i poder procedir al seu estudi, per tal de conèixer una mica millor aquest exemple del Renaixement a casa nostra, cosa que no passa amb altres edificis que no han tingut aquesta sort i dels quals no podem seguir el rastre.

Judith Urbano

Doctora en Història de I'Art. Universitat Internacional de Catalunya Grup de Recerca GRACMON, Universitat de Barcelona jurbano@uic.es
7 Expedient 995-(7p) a I'Arxiu Administratiu Municipal de Barcelona. Consta dels plànols següents: planta del solar amb la casa que s'ha de tirar i la nova, jardí i cotxera, planta baixa, façana oest, sud i nord i secció, planta principal i primer pis. Signats el 24 de juliol de 1907 per August Font i la marquesa de Casa Brusi. Al fons August Font de I'Arxiu del COAC també hi ha tres plànols sota l'entrada "Casa pel Marquès de Brusi»: H102C/ 6/3088 situació, planta i alçats; H102C/6/3089 planta, alçats i entrada, i H102C/6/ 3090 secció del pati gòtic de la Casa Gralla.

8 Miquel CAnals ElíasBrusi, La casa Brusi y el Diario de Barcelona, Barcelona, Ajuntament de Barcelona, 2010, p. 291.

9 Octavi Mestre, Espacios para vivir y trabajar, Barcelona, Monsa, 2008, p. 157. 


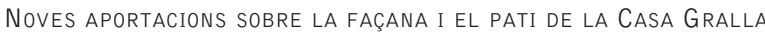

Aquest estudi aporta més informació sobre tres aspectes de la Casa Gralla poc coneguts i escassament abordats per la historiografia: les pedres originals que encara existeixen a la Torre Pallaresa de Santa Coloma de Gramenet; la decoració de la façana renaixentista a partir dels dibuixos originals de Francesc Soler i Rovirosa, que han sortit a la llum quan es consideraven perduts, i el projecte d'August Font i Carreras, de 1907, per adaptar la nova casa de la marquesa de Brusi al pati de la Casa Gralla, traslladat per ell mateix a la finca el 1882.

Paraules clau: Casa Gralla, Renaixement, Torre Pallaresa, August Font i Carreras, Francesc Soler i Rovirosa

New contributions on the Casa Gralla's FAÇAde And COURTyard

This study aims to present more information about three of the least explored and seldom addressed aspects in the historiography of Casa Gralla: the original stones still extant in Torre Pallaresa, in Santa Coloma de Gramenet; the decoration of the Renaissance façade, from the original drawings by Francesc Soler i Rovirosa, which were thought to be lost but were recently discovered; and the 1907 project by August Font i Carreras to adapt the Marquise of Brusi's new house to the courtyard of Casa Gralla, which Font i Carreras had already relocated to her property in 1882.

Keywords: Casa Gralla, Renaissance, Torre Pallaresa, August Font i Carreras, Francesc Soler i Rovirosa. 